\title{
APPLICABILITY OF PRINCIPLE OF SUPERPOSITION IN OBTAINING HORIZONTAL IMPEDANCE FUNCTIONS OF PILE GROUPS UNDER SOIL NONLINEARITY
}

\author{
Chandra S. Goit ${ }^{*}$, Masato Saitoh ${ }^{1}$, and George Mylonakis ${ }^{2}$ \\ ${ }^{1}$ Department of Civil and Environmental Engineering, Saitama University \\ 255 Shimo-Okubo, Saitama, Japan \\ chandra@kiban.civil.saitama-u.ac.jp* \\ saity@mail.saitama-u.ac.jp \\ ${ }^{2}$ Department of Civil Engineering, University of Patras \\ 25600 Patras, Greece \\ mylo@upatras.gr
}

Keywords: Pile-to-pile interaction, horizontal impedance functions, principle of superposition, soil nonlinearity

\begin{abstract}
The effects of soil nonlinearity on the pile-to-pile horizontal interaction factors and horizontal impedance functions of piles through model testing are investigated. Separate experiments with a solitary pile and closely spaced 3x3-pile groups with spacing to diameter ratio of 2.5 embedded in cohesionless soil, are considered. Lateral harmonic pile-head loadings in the form of accelerations with amplitudes of $0.2,0.5,1$ and $2 \mathrm{~m} / \mathrm{s}^{2}$ for a wide range of frequencies are reported. Results obtained from model soil-pile systems encased in a laminar shear box show that local nonlinearity and resonant behavior of soil have a significant impact on both the interaction factors and the impedance functions. Utilizing the measured values of horizontal impedance functions of a single pile and the horizontal pile-to-pile interaction factors, Poulos' superposition method is assessed in obtaining the horizontal impedance functions of the pile group. Comparisons between computed and experimentally measured values show very good agreement, suggesting that the principle of superposition is applicable under nonlinear conditions.
\end{abstract}




\section{INTRODUCTION}

Safe and efficient design of pile-supported structures depends on the reliable prediction of the response of soil-pile-structure systems, rather than that of the individual components treated separately. For such, the consideration of soil-structure interaction effects in the analysis is essential. The horizontal impedance functions (IF) of piles are an important component in the analysis of laterally loaded soil-pile-structure systems with the consideration of soil-structure interactions. These horizontal IF are complex-valued, frequency dependent quantities and are expressed by their real and imaginary parts as

$$
K_{h h}^{*}=k_{h h}+i C_{h h}
$$

where $k_{h h}$ and $C_{h h}$ are the real and imaginary parts of the complex pile-head horizontal IF, respectively. The real part reflects the stiffness of the soil-pile system, while the imaginary part reflects the damping in the form of material and radiation energy dissipation. It is noteworthy that the IF for a pile group is different from that of a single pile, as pile-to-pile interaction exists in a group of piles.

The superposition method initially suggested by Poulos for static loads [1] and later extended by various investigators to the dynamic regime ([2], [3], [4], [5]), where it is assumed that the interaction effects between the individual piles pairs can be superimposed, have been extensively used for the computation of pile group response once the IF of a single pile and interaction factors between pairs of piles in the distances and frequencies of interest are known. A number of elasticity-based approximate solutions for computing the pile-to-pile interaction factors are available ([2], [3]). In addition, analytical solutions for obtaining the IF of single piles are also available [1]. However, formulation of these available solutions relies upon the assumption that both the pile and soil behave elastically. It is well known that under strong excitation, soil near a pile behaves nonlinearly and has a strong influence on the response, which cannot be captured by elastic considerations.

The article at hand reports on an experimental investigation of soil-pile systems in assessing the applicability of Poulos' superposition method under strong dynamic excitation. Three distinct sets of experiment are carried out for: (a) horizontal IF's of single piles, (b) pile-to-pile interaction factors, and (c) horizontal IF's of pile groups. Fixed-head floating piles are considered, except for the testing involving pile-to-pile interaction where free head conditions were maintained. Closely spaced pile group configurations consisting of $3 \times 3$ piles with spacing-to-diameter ratio (s/d) of 2.5 are reported. Experiments consider both the effects of resonance and local nonlinearities of soil due to applied loads at the pile-head.

\section{EXPERIMENTAL PROGRAM}

\subsection{Law of similitude}

In model testing, as the response of a model differs from that of the true prototype, scaling laws are fundamental in correlating the response of the two systems. Early procedures are derived by Rocha [6] and Roscoe [7], who discuss scaling relations between model and prototype in terms of stress and strain. Additional work was carried out by Kagawa [8], Kokusho and Iwatate [9], in generalizing the theory to more general conditions. For the present investigation, scaling laws derived by Kokusho and Iwatate [9] under one- $g$ testing environment are employed. 
Table 1 summarizes the scaling relationship used in the present study where $\lambda$ is the geometric scaling ratio of the model to the prototype and $\eta$ is the density scaling ratio of the model to the prototype.

\begin{tabular}{l|cc|rrr|l}
\hline \multirow{2}{*}{ Items } & \multicolumn{2}{|c|}{ Similitude } & \multicolumn{3}{|c|}{ Scaling factors } & \multirow{2}{*}{ Units } \\
\cline { 2 - 5 } & Law & Factor & Prototype & Model & Attained & \\
\hline Length of pile $(\mathrm{l})$ & $\lambda$ & 0.05 & 18.0 & 0.90 & 0.90 & $\mathrm{~m}$ \\
Depth of soil $(\mathrm{H})$ & $\lambda$ & 0.05 & 20.0 & 1.00 & 1.00 & $\mathrm{~m}$ \\
Diameter of pile $(\mathrm{d})$ & $\lambda$ & 0.05 & 0.80 & 0.04 & 0.04 & $\mathrm{~m}$ \\
Density of pile $\left(\rho_{\mathrm{p}}\right)$ & $\eta$ & 0.81 & 2.40 & 1.95 & 1.21 & $\mathrm{t} / \mathrm{m}^{3}$ \\
Density of soil $\left(\rho_{\mathrm{s}}\right)$ & $\eta$ & 0.81 & 1.80 & 1.46 & 1.46 & $\mathrm{t} / \mathrm{m}^{3}$ \\
Young's modulus of pile $\left(\mathrm{E}_{\mathrm{p}}\right)$ & $\eta^{1 / 2} \lambda^{1 / 2}$ & 0.20 & 25.0 & 5.04 & 3.20 & $\mathrm{GPa}$ \\
Shear wave velocity $\left(\mathrm{V}_{\mathrm{s}}\right)$ & $\eta^{-1 / 4} \lambda^{1 / 4}$ & 0.50 & 171.5 & 85.44 & 95.72 & $\mathrm{~m} / \mathrm{s}$ \\
Natural frequency of soil $\left(\mathrm{f}_{\mathrm{n}}\right)$ & $\eta^{-1 / 4} \lambda^{-3 / 4}$ & 9.96 & 2.14 & 21.36 & 23.93 & $\mathrm{~Hz}$ \\
\hline
\end{tabular}

Table 1: Scaling relations for model testing

\subsection{Experimental setup}

The experimental model consisted of soil-pile systems cased in a laminar shear box (1200 $\mathrm{mm} \times 800 \mathrm{~mm} \times 1000 \mathrm{~mm}$ ) bolted on a uniaxial shaking table.

\subsubsection{Soil}

Homogenous dry Gifu sand was employed, the standard properties of which are available as published by Ishida et al. [10]. The desired density of sand was attained by compaction through base vibration of the shear box at frequency of $40 \mathrm{~Hz}$ and amplitude of $5 \mathrm{~m} / \mathrm{s}^{2}$.

\subsubsection{Single pile}

A solid cylindrical acrylic pile with the diameter $\mathrm{d}=40 \mathrm{~mm}$ and length $1=900 \mathrm{~mm}$ having a pile-head $(125 \mathrm{~mm} \times 125 \mathrm{~mm} \times 125 \mathrm{~mm})$ was used. The pile-head was fixed with an actuating device ensuring that only horizontal displacement is applied in that elevation. No contact between pile-head and soil was allowed.

\subsubsection{Pile group}

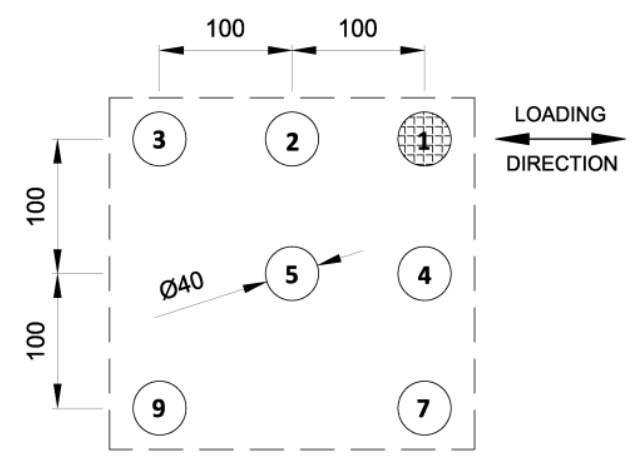

(a) pile-to-pile interaction (dimensions in $\mathrm{mm}$ )

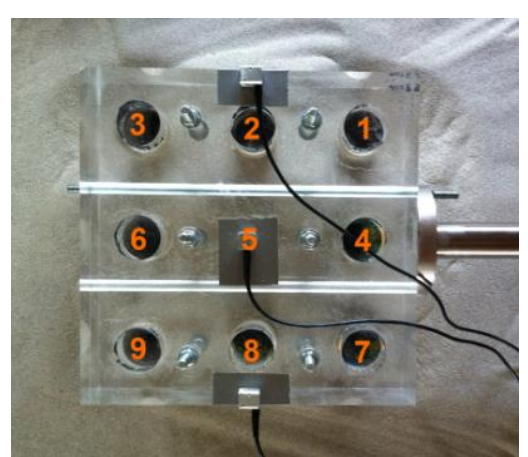

(b) pile group

Figure 1: Layout of pile group 
Nine solid acrylic piles capped by a solid acrylic pile-cap with thickness of $100 \mathrm{~mm}$ were used to form a $3 \times 3$ pile group with $\mathrm{s} / \mathrm{d}=2.5$ as shown in Figure 1(b). The pile-cap was connected to the horizontal actuator as in the case of the single pile, such that only horizontal translation was allowed. In addition, no contact between pile-cap and soil was allowed.

A similar layout was used for the measurement of pile-to-pile interaction factors, but without the pile-cap. Pile 1, as shown in Figure 1(a), was fixed to the horizontal actuator while all the other piles were free head piles. Horizontal interaction factors for piles in line to the direction of loading (pile 2 and 3) and perpendicular to the direction of loading (pile 4 and 7) were measured. Horizontal interaction factors for all the other piles (i.e., 5, 6, 8 and 9) are straightforwardly computed by simple trigonometric expressions ([2], [4]), based on piles 2 , 3,4 and 7.

\subsubsection{Loading}

Four different amplitudes of lateral harmonic accelerations $\left(0.2,0.5,1,2 \mathrm{~m} / \mathrm{s}^{2}\right)$ at the pilehead level are considered to test the system in low-to-high strain levels in soil, for the frequency range of $9 \sim 35 \mathrm{~Hz}$.

\section{RESULTS}

The measured data from the experiments are processed in the frequency domain and are presented in this section. Resonance of the soil-pile systems is distinctly observed for all loading amplitudes within the measured range of frequencies.

\subsection{Horizontal impedance functions of single pile}

Horizontal IF of a single pile subjected to different amplitudes of pile-head harmonic loadings are presented in Figure 2. Real part of the IF in the measured range of frequencies does not show a definite trend among the loading amplitudes. Considering the global nonlinearity of soil, the pile-head stiffness is expected to decrease with the increase in loading amplitude, however, no clear pattern is observed. On the other hand, the imaginary part shows an increase in value with increasing loading amplitude, distinctly in the low-frequency region.

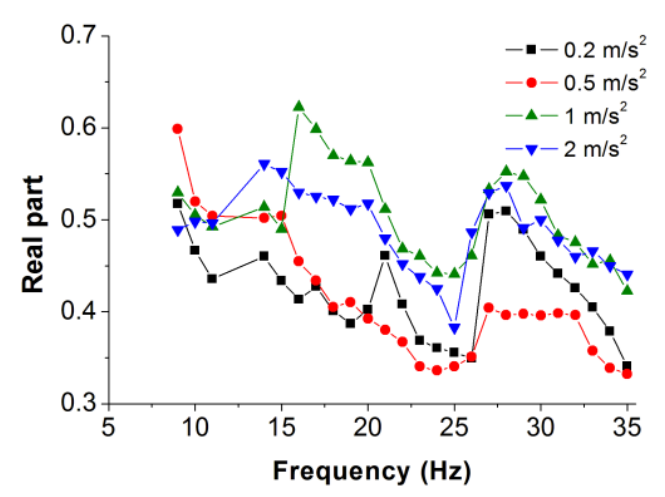

(a) real part

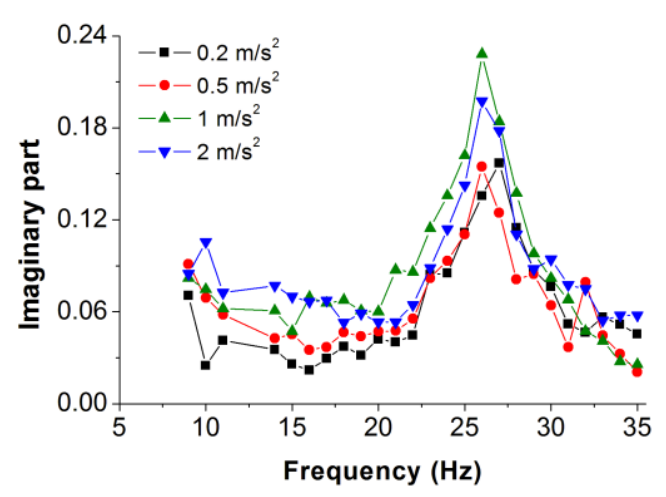

(b) imaginary part

Figure 2: Horizontal impedance functions of a single pile (in $\mathrm{kN} / \mathrm{mm}$ )

\subsection{Horizontal pile-to-pile interaction factors}

Measured dynamic pile-to-pile horizontal interactions for the highest amplitude of loading utilized in present work (i.e., $2 \mathrm{~m} / \mathrm{s}^{2}$ at the pile head) are presented in Figure 3. 
In the low-frequency range, pile 2 exhibits the highest value of interaction factor. On the other hand, pile 3, which is at a distance twice that of the pile 2 shows a very small value of interaction factors, suggesting that the interaction between pile 1 and pile 3 is not so significant. High-frequency region, on the other hand, exhibits similar behavior as of the lowfrequency region (i.e., pile 2 shows the higher value of interaction factors). The imaginary part shows out of phase movement with identical peak values.
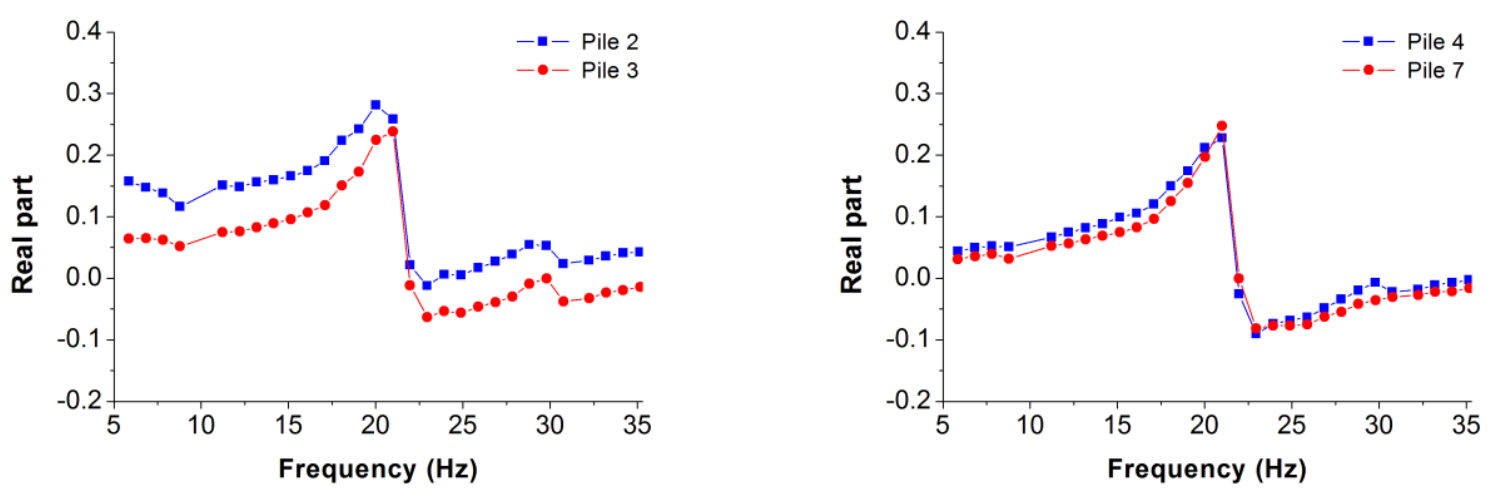

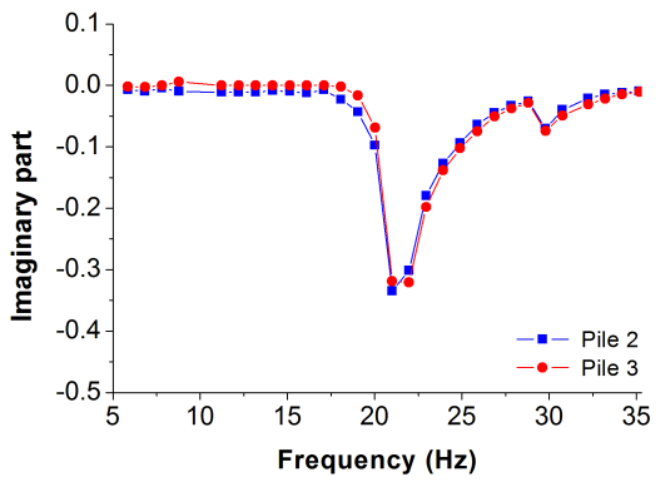

(a) pile 2 and 3

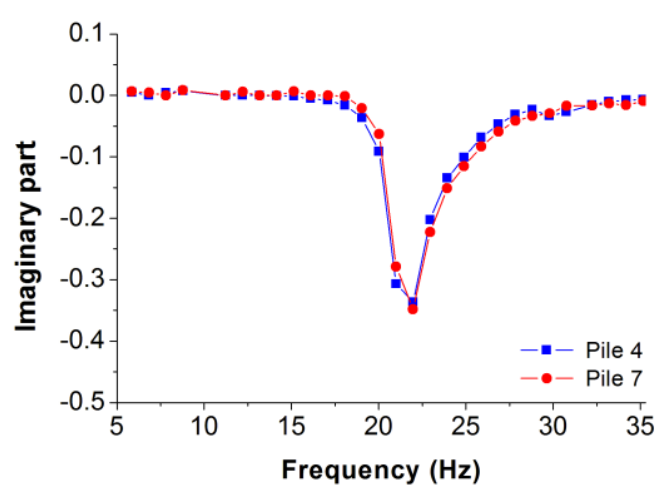

(b) pile 4 and 7

Figure 3: Horizontal pile-to-pile interaction factors

Pile-to-pile interaction in the direction perpendicular to loading (i.e., pile 4 and 7 ) is found to be minimal. The low-frequency region shows a negligible increase in the value of the horizontal interaction factor for pile 4. Around resonant frequency, peak values of the horizontal interaction factor for both the piles 4 and 7 are nearly identical. The imaginary part also shows identical peak values.

\section{PRINCIPLE OF SUPERPOSITION}

Utilizing Poulos' superposition method [1], the horizontal IF for pile groups can be written as function of the corresponding IF for single piles and pile-to-pile interaction factors. Displacement of individual piles in a group based on identical load carrying capacity of a pile can be written straightforwardly as function of solitary pile stiffness and the applied force. The procedure is detailed in Dobry and Gazetas [2].

Based on the experimentally measured horizontal IF of a single pile and the horizontal interaction factors, horizontal IF of the 3x3-pile group is computed with Poulos' superposition method. Such obtained pile groups' horizontal IF are compared with the experimentally obtained horizontal IF for the 3x3-pile group. Also compared are the results with no considera- 
tion for group effect, i.e., sum of individual stiffness of piles in the pile group with no account for the pile-to-pile interaction factors.

For all loading amplitudes, the comparisons between the computed and experimentally obtained results show a very good agreement, asserting that the Poulos' superposition method is applicable under nonlinear conditions. Furthermore, results indicate significant influence of group effect on the response of pile groups, as anticipated. Figures 4 and 5 show the comparisons for the lowest $\left(0.2 \mathrm{~m} / \mathrm{s}^{2}\right)$ and highest $\left(2 \mathrm{~m} / \mathrm{s}^{2}\right)$ loading amplitudes utilized in present work.
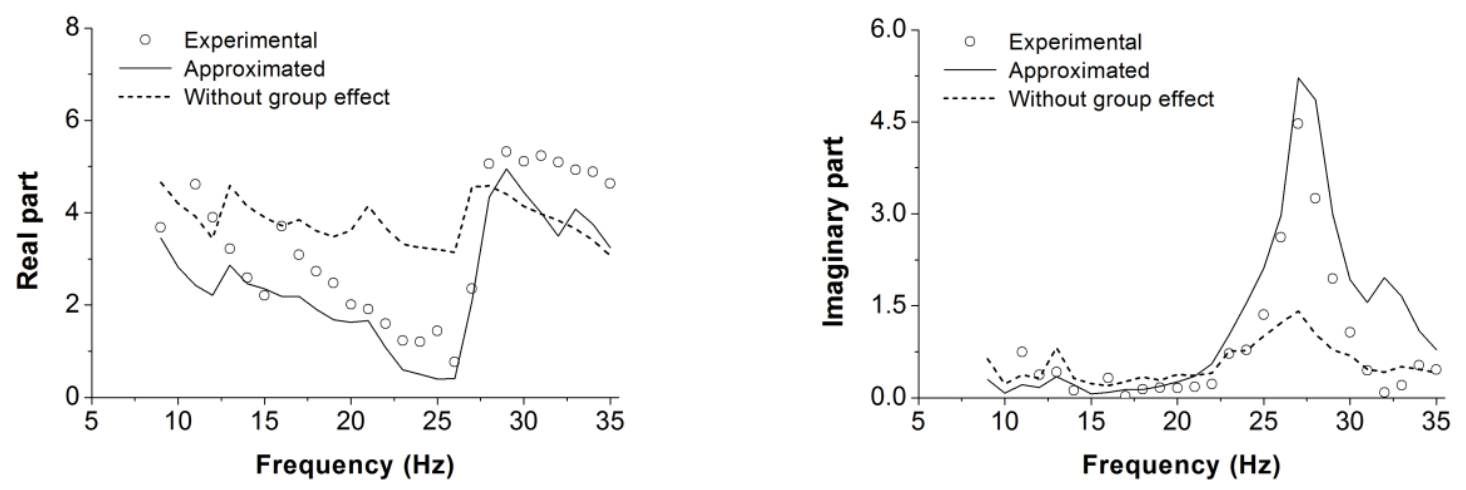

Figure 4: Horizontal impedance functions of a 3x3-pile group (in $\mathrm{kN} / \mathrm{mm}$ ) for $0.2 \mathrm{~m} / \mathrm{s}^{2}$
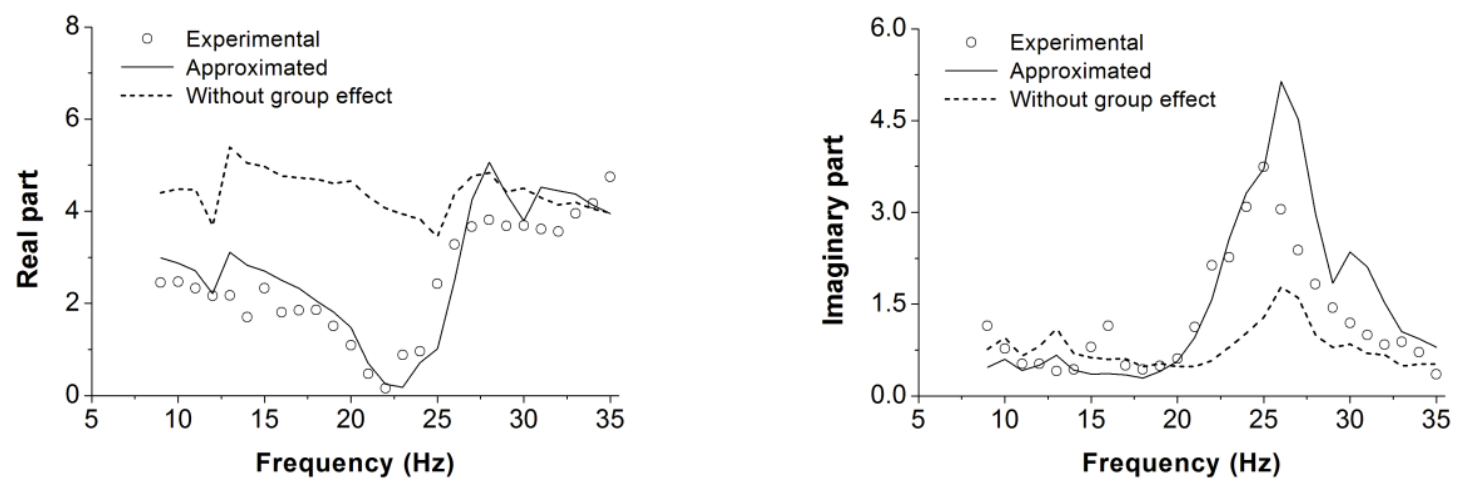

Figure 5: Horizontal impedance functions of a 3x3-pile group (in $\mathrm{kN} / \mathrm{mm}$ ) for $2 \mathrm{~m} / \mathrm{s}^{2}$

\section{CONCLUSIONS}

The reported experimental work was carried out for assessing the applicability of Poulos' superposition method under strong loading conditions, encompassing both the effect of soil nonlinearity and resonance of the soil-pile system. Comparisons between computed and experimentally measured values of horizontal impedance functions for the pile group show a very good agreement, suggesting that the principle of superposition can be used for practical conditions even in presence of considerable nonlinearity.

\section{ACKNOWLEDGMENT}

This paper was supported by JSPS Grant-in-Aid for Scientific Research (C) No. 23560562. Any opinions, findings, conclusions, or recommendations expressed in this material are those of the authors and do not necessarily reflect the views of the sponsors. 


\section{REFERENCES}

[1] H.G. Poulos and E.H. Davis, Pile foundation analysis and design. John Wiley \& Sons, New York, 1980.

[2] R. Dobry and G. Gazetas, Simple method for dynamic stiffness and damping of floating pile groups. Géotechnique, 38(4), 557-574, 1988.

[3] G. Gazetas, K. Fan, A. Kaynia and E. Kausel, Dynamic interaction factors for floating pile groups. Journal of Geotechnical Engineering, ASCE, 117(10), 1531-1548, 1991.

[4] A.M. Kaynia, and E. Kausel, Dynamic stiffness and seismic response of pile groups. Research Report, R82-03, Massachusetts Institute of Technology, 1982.

[5] G. Mylonakis, Contribution to static and seismic analysis of piles and pile-supported bridge piers, $\mathrm{PhD}$ thesis, University of New York at Buffalo.

[6] M. Rocha, The possibility of solving soil mechanics problems by the use of models. Proceedings of the Fourth International Conference on Soil Mechanics, London, Vol. 1, 183-188, 1957.

[7] K.H. Roscoe, Soils and model tests. The Journal of Strain Analysis for Engineering Design, 3(1), 57-64, 1968.

[8] T. Kagawa, On the similitude in model vibration tests of earth-structures. Proceedings of Japan Society of Civil Engineers (275), 69-77, 1978. [in Japanese].

[9] T. Kokusho and T. Iwatate, Scaled model tests and numerical analyses on nonlinear dynamic response of soft grounds. Proceedings of Japanese Society of Civil Engineers, (285), 57-67, 1979 [in Japanese].

[10] T. Ishida, H. Watanabe, H. Ito, Y. Kitahara and M. Matsumoto, Static and dynamic mechanical properties of sandy materials for model tests of slope failure under the condition of low confining stress. Research Report of Electrical Power Center Research Institute, No. 380045, 1981 [in Japanese]. 